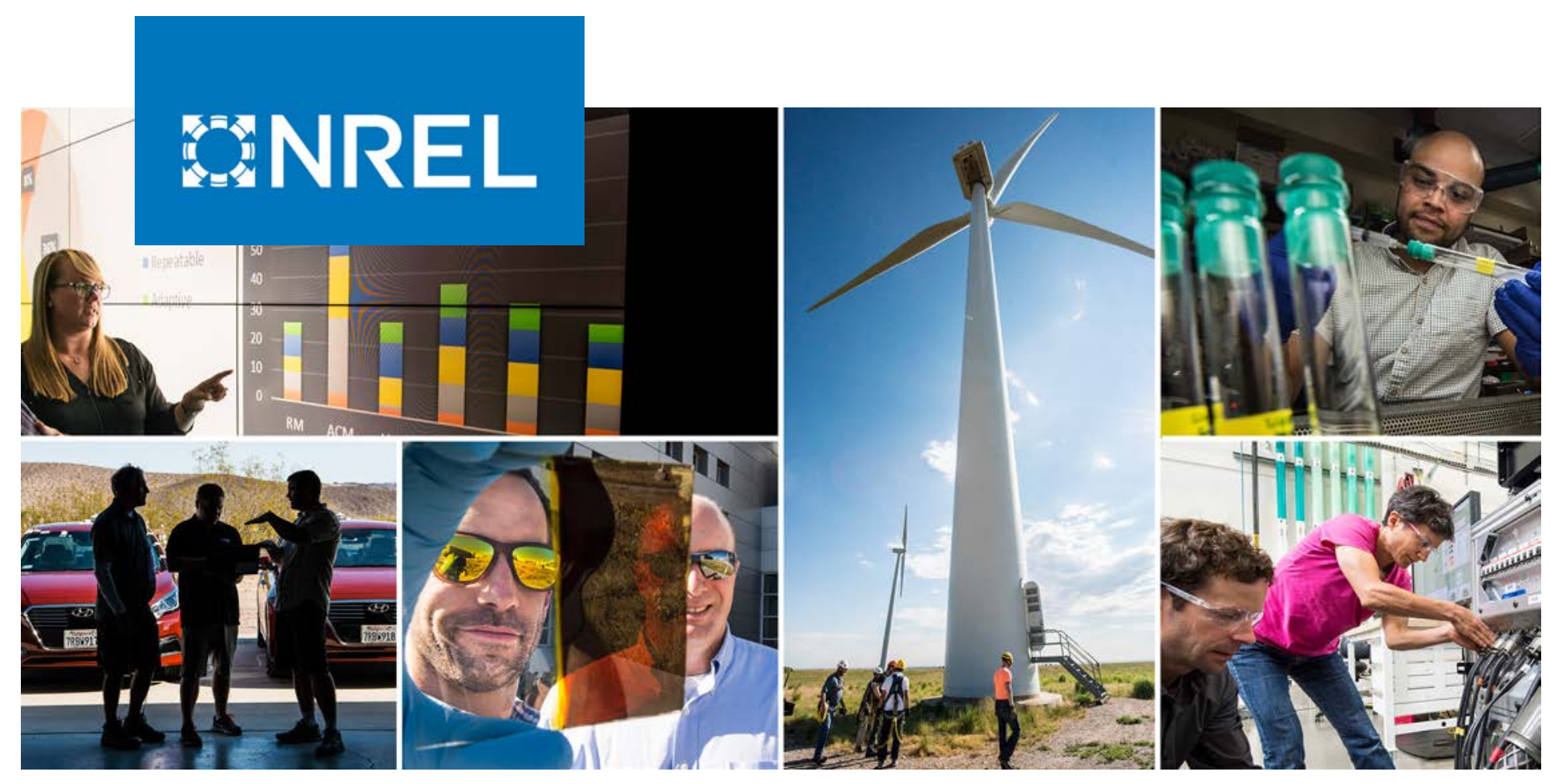

\title{
A Review of Degradation Behavior and Modeling of Capacitors
}

\section{Preprint}

\author{
Anunay Gupta, ${ }^{1}$ Om Prakash Yadav, ${ }^{1}$ Douglas DeVoto, ${ }^{2}$ \\ and Joshua Major ${ }^{2}$
}

1 North Dakota State University

2 National Renewable Energy Laboratory

Presented at the American Society of Mechanical Engineers (ASME) 2018 International Technical Conference and Exhibition on Packaging and Integration of Electronic and Photonic Microsystems (InterPACK 2018) San Francisco, California August 27-30, 2018

NREL is a national laboratory of the U.S. Department of Energy Office of Energy Efficiency \& Renewable Energy

Operated by the Alliance for Sustainable Energy, LLC

This report is available at no cost from the National Renewable Energy Laboratory (NREL) at www.nrel.gov/publications.

\section{Conference Paper}

NREL/CP-5400-71386

October 2018 


\title{
GNREL
}

\section{A Review of Degradation Behavior and Modeling of Capacitors}

\section{Preprint}

\author{
Anunay Gupta, ${ }^{1}$ Om Prakash Yadav, ${ }^{1}$ Douglas DeVoto, ${ }^{2}$ \\ and Joshua Major ${ }^{2}$ \\ 1 North Dakota State University \\ 2 National Renewable Energy Laboratory
}

Suggested Citation

Anunay Gupta, Om Prakash Yadav, Douglas DeVoto, and Joshua Major. 2018. A Review of Degradation Behavior and Modeling of Capacitors: Preprint. Golden, CO: National Renewable Energy Laboratory. NREL/CP-5400-71386. https://www.nrel.gov/docs/fy19osti/71386.pdf.

NREL is a national laboratory of the U.S. Department of Energy Office of Energy Efficiency \& Renewable Energy Operated by the Alliance for Sustainable Energy, LLC

This report is available at no cost from the National Renewable Energy Laboratory (NREL) at www.nrel.gov/publications.

Contract No. DE-AC36-08GO28308
Conference Paper NREL/CP-5400-71386

October 2018

National Renewable Energy Laboratory 15013 Denver West Parkway Golden, CO 80401

303-275-3000 • www.nrel.gov 


\section{NOTICE}

This work was authored in part by the National Renewable Energy Laboratory, operated by Alliance for Sustainable Energy, LLC, for the U.S. Department of Energy (DOE) under Contract No. DE-AC36-08GO28308. Funding provided by the U.S. Department of Energy Office of Energy Efficiency and Renewable Energy Vehicle Technologies Office. The views expressed herein do not necessarily represent the views of the DOE or the U.S. Government. The U.S. Government retains and the publisher, by accepting the article for publication, acknowledges that the U.S. Government retains a nonexclusive, paid-up, irrevocable, worldwide license to publish or reproduce the published form of this work, or allow others to do so, for U.S. Government purposes.

This report is available at no cost from the National Renewable Energy Laboratory (NREL) at www.nrel.gov/publications.

U.S. Department of Energy (DOE) reports produced after 1991 and a growing number of pre-1991 documents are available free via www.OSTI.gov.

Cover Photos by Dennis Schroeder: (clockwise, left to right) NREL 51934, NREL 45897, NREL 42160, NREL 45891, NREL 48097, NREL 46526 .

NREL prints on paper that contains recycled content. 


\section{A REVIEW OF DEGRADATION BEHAVIOR AND MODELING OF CAPACITORS}

\author{
Anunay Gupta \\ North Dakota State University \\ Fargo, ND, USA \\ Douglas DeVoto \\ National Renewable Energy Laboratory \\ Denver, CO, USA
}

\author{
Om Prakash Yadav \\ North Dakota State University \\ Fargo, ND, USA \\ Joshua Major \\ National Renewable Energy Laboratory \\ Denver, CO, USA
}

\begin{abstract}
This paper firstly reviews the failure causes, modes and mechanisms of two major types of capacitors used in power electronic systems - metallized film capacitors and electrolytic capacitors. The degradation modeling related to these capacitors is then presented. Both physics-of-failure and data-driven degradation models for reliability and lifetime estimation are discussed. Based on the exhaustive literature review on degradation modeling of capacitors, we provide a critical assessment and future research directions.
\end{abstract}

\section{INTRODUCTION}

Capacitors in power electronics are used for a wide variety of applications, including energy storage, ripple voltage filtering, and DC voltage smoothing. The two major types of capacitors used in power electronic systems are aluminum electrolytic capacitors and metallized film capacitors. The state of health, or life, of these capacitors depends on stress factors like temperature, voltage, ripple current, chargedischarge, and humidity. Various degradation measures such as capacitance, equivalent series resistance, dissipation factor, and insulation resistance have been used to monitor the degradation state of capacitors. To capture the degradation behavior in a shorter time, several acceleration models are used to replicate the specific failure behavior. The acceleration models are usually based on the physics underlying a particular failure mechanism. Some common acceleration models used in capacitor lifetime prediction are the Arrhenius law for temperature, inverse power law for voltage and humidity stresses, and Eyring law for capturing the interaction of other stress factors with temperature stress. The major limitation of acceleration models is their inability to track the capacitor degradation with time. That is, the acceleration models cannot predict the state, or health, of a capacitor at a particular time. Hence, there is a need for data-driven or statistical degradation models to ascertain the capacitor's actual state of health at a given time and subsequently estimate their reliability and remaining useful life. Several efforts have been made to model degradation behavior of the capacitor considering either physics-of-failure models or statistical models and subsequently estimate its reliability and lifetime parameters. This paper reviews the behavior and the degradation modeling of these capacitors for reliability assessment and lifetime analysis.

\section{FAILURE ANALYSIS}

Capacitors could fail due to various factors like manufacturing and design defects, material wear out, operating temperature, voltage, current, humidity and mechanical stress. Wear-out failures signify the end of useful life of a product, and this section is mainly concerned with the wear-out failures in DC-link capacitors. Electrolyte evaporation is the primary wear-out mechanism in electrolytic capacitors and is caused by high temperatures within the capacitor core. In the case of metallized film capacitors, self-healing or localized dielectric breakdown due to overvoltage is the main wear-out mechanism. These failure mechanisms and their root causes, along with the other causes of capacitor failure are discussed in detail in the following section.

\subsection{Metallized Film Capacitors}

Metallized film capacitors consist of dielectric films with a metallic coating on the surface. The electrodes are composed of very thin layers (20 to $100 \mathrm{~nm}$ ) of metal, usually aluminum or zinc, evaporated onto the surface of the polymer film. The most common dielectric films that are used in the industry are mainly polypropylene (PP) or polyethylene terephthalate (PET). In special applications, dielectrics such as polyethylene naphthalene or polyphenylene sulfide are used for hightemperature operating conditions (up to $150^{\circ} \mathrm{C}$ ). PET film capacitors have higher capacitance per volume than PP film capacitors due to their high dielectric constant and availability in thin gauges. They also have a better mechanical resistance and a slightly higher exploitation temperature than PP film capacitors, with operating temperatures up to $125^{\circ} \mathrm{C}$. The negative point is that the loss factor is ten times larger, which means a ten-fold increase in temperature elevation for the same rated power. PP film has superior electrical characteristics. PP film capacitors exhibit very little capacitance change over time with an applied voltage, making them ideal for applications where a stable level of capacitance is needed. The temperature and frequency dependencies of electrical parameters for PP film capacitors are very low. These capacitors may be operated up to $100^{\circ} \mathrm{C}$. The dissipation factor of PP film capacitors is smaller than that of other film capacitors. Also, the PP film material absorbs less moisture than PET film [1-3].

Metallized film capacitors have a unique self-healing ability. If there is a micro-void or defect in the dielectric film and the capacitor is connected to a voltage of a sufficient level (electric-field stress), a glow discharge occurs in the micro-void. This discharge generates heat due to a high current density in the breakdown region, which causes evaporation of the electrode layer around the void. The damaged part is disconnected from the capacitor and cannot degrade its performance. 
This is accompanied by a slight decrease in the capacitance [4]. Metallized film capacitors have this significant advantage of selfhealing over general film capacitors or non-metallized film capacitors. In non-metallized film capacitors, when an overvoltage is applied and small localized dielectric breakdown occurs, the exposed electrodes make contact with each other and short, rendering the capacitor useless. In case of metallized films, the combination of the electrode foil thinness and the high energy density in the fault area causes the foils to vaporize and the capacitor stays in operation and avoids catastrophic failure. This phenomenon is termed as "self-healing" [5]. The selfhealing or clearing process in metallized film capacitors depends on three factors, namely, the working voltage, mechanical pressure between the winding layers, and metallization thickness (resistivity) [6]. Accumulation of these self-healing events over time, causes a "soft" failure of the metallized film capacitor when the capacitance value decreases by a certain percentage of the initial capacitance. The definition of this soft failure (end-of-life criterion) varies from manufacturer to manufacturer and between applications. With time, the pressure inside the capacitor casing increases due to production of vaporized metal by self-healing events. This can eventually cause a catastrophic failure either through the pressure, increasing enough to burst the capacitor casing, or the vaporized metal concentration increasing enough to become conductive and cause a flashover event [ 7 , 8]. Upon an increase in the working voltage, the self-healing time increases, and the heating of adjacent insulator layers becomes significant, which can be destructive for the structure of the capacitor [9]. Li et al. [10] investigated the influence of temperature and voltage on the life of metallized film capacitors and the temperature dependence of this self-healing characteristic. It is found that a catastrophic failure is more likely to happen under elevated working temperature and voltages due to the decrease in breakdown electric field strength of the capacitor with a rise in temperature. During the self-healing process, there is an energy discharge of stored energy. This discharge of energy under the same breakdown voltage becomes larger under higher temperature conditions.

Temperature alone does not seem to play a major part in the degradation of metallized film capacitors. At elevated temperatures, the mechanical properties of dielectric films change and their volume increases due to thermal expansion. Hence, thermal stress occurs due to the difference between coefficients of the thermal expansion of the dielectric film and electrode metallization on the film, which can influence the structure of the metal film. Research work and experiments conducted in [11] point out significant changes in the non-linearity of current-voltage characteristics of metallized PP film capacitors during accelerated thermal aging, as compared to negligible change in capacitance. These changes are proposed to be due to the deterioration in quality of the electrode metallization from temperature stresses. Apart from voltage and temperature, another important stress factor especially in case of DC link capacitors is the ripple current. By definition, a ripple current is an $\mathrm{AC}$ current through the capacitor due to incomplete suppression of the alternating waveform within the power supply. Root mean square (RMS) is a method of denoting the AC waveform as DC value that will produce the same heating effect, or power dissipation in the circuit. The ability of a capacitor to withstand a continuous RMS current depends on the frequency of the electrical stress and thermal power dissipation of the component. If the power generated by the capacitor body is greater than the power that can be dissipated by its surface, increased self-heating may occur. Self-heating increases the capacitor temperature, leading to a reduction of the breakdown voltage and, in the worst cases, even melting of the capacitor [1]. The self-heating temperature of a capacitor depends on equivalent series resistance (ESR), on the current across the capacitor, and on the thermal resistance between the case and the ambient temperature. The combination of high ripple current and voltage leads to electrochemical corrosion of the thin electrode metallization, gradually converting aluminum to aluminum oxide. The corrosion process involves the migration of oxygen and/or moisture of the polymer to the polymer/metallization interface. It is dependent on temperature, electrode thickness, stress, and frequency [2, 12, 13]. Metallized film capacitors using PP as the dielectric are less affected by the ripple current than ones with a PET dielectric.

The effect of $\mathrm{AC}$ voltage and temperature on the degradation of metallized film capacitors is studied in [14] and a life model involving all the main stressing factors (peak voltage, RMS value, and temperature) is proposed, using multivariate regression. It is found that the peak voltage has the most significant effect on capacitor aging. Although thermal aging contributes to degradation, its significance is less than the degradation due to peak voltage and RMS voltage. The detachment of the "sprayed ends" or the schoopage from the capacitor roll is commonly found in pulsed power applications, and it normally results in an open-circuit failure [15]. The combined effect of electrical, thermal, and mechanical stresses gradually leads to the degradation of contact and eventually, the detachment of the sprayed ends. The high current peaks are mainly responsible for these effects, independent of the waveform energy content. As the contact is degraded, the ESR value, and consequently, the loss factor $(\tan \delta$ ) will greatly increase according to the number of pulses applied to the capacitor [16].

The degradation of metallized film capacitors is a concern in applications exposed to high humidity environments. The metallized electrode layer in metallized film capacitors is very thin, typically less than $50 \mathrm{~nm}$, which is susceptible to corrosion due to the ingress of atmospheric moisture. The normal protective surface oxide formation may be comparable in thickness to that of the metal film. Corrosion usually progresses from the ends of the capacitor cylinder to the middle, related to the ingress of atmospheric moisture. Corrosion of metallized electrodes leads to an uneven distribution of current, which causes localized heating and eventually leads to catastrophic failure [17]. Regarding the effect of geometry of metallized film capacitors with the same specifications but different heights, experiments conducted by [18] show that long capacitors deteriorate faster than plate-shaped ones, due to higher heating under the same electrical stress.

\subsection{Electrolytic Capacitors}

Electrolytic capacitors are composed of an electrolyte-impregnated paper layer sandwiched between two highly roughened metal foils (usually aluminum). Grown directly onto the anode foil is a thin, highquality oxide, which acts as a dielectric possessing excellent breakdown voltage characteristics. One of the primary functions of electrolytic capacitors is the smoothing of voltage ripple and storing electrical energy. Electrolytic capacitors provide high capacitance values, high volumetric efficiency, and an excellent price over performance ratio. However, the electrolytic capacitor has the shortest lifespan of the components in power electronics. Electrolytic capacitors tend to degrade and fail much faster under high electrical or thermal stress 
operating conditions than metallized film capacitors. The failures in electrolytic capacitors can be categorized into catastrophic and wear-out failures. The wear-out of electrolytic capacitors leads to the drift in the values of two important parameters, capacitance and ESR. The drift in these parameters ultimately leads to failure of the capacitor. Defined industry standards specify the end-of-life of an electrolytic capacitor under thermal stress if the capacitance value decreases by $10 \%$ and the ESR value increases by $250 \%$ or more from its initial rated value. Similarly, under electrical stress operations, the end-of-life is defined by its ESR increasing by $280 \%-300 \%$ over and capacitance decreasing by $20 \%$ below its initial condition values. The ratings are different for electrical and thermal stress conditions because thermal stress conditions are considered for situations when the capacitor is in storage, and not in operation $[19,20]$.

The primary failure mechanism of an electrolytic capacitor is the evaporation of the electrolyte due to thermal overstress. A capacitance decrease and an ESR increase are caused by the loss of electrolyte, by diffusion (as vapor) through the sealing material in the wear-out failure period. If the electrolyte vapor pressure within the capacitor increases, by high temperatures for example, the diffusion rate increases. Factors that can increase the capacitor temperature, such as ambient temperature and ripple current, accelerate capacitor wear-out. Hence, estimating the temperature of the capacitor element (capacitor core) is of vital importance. The actual temperature of the capacitor element can be greater than the ambient temperature due to the temperature rise in applications with ripple current. Wear-out can also be accelerated by high internal pressure caused by gas generation from excessive leakage current or attack of the cathode foil by electrolyte (oxide breakdown, which is mainly observed under electrical overstress conditions) [2126]. Table 1 summarizes the major failure causes, mechanisms and modes of aluminum electrolytic capacitors and metallized film capacitors, mainly concerned with the field aging or application phase of capacitors.

TABLE 1. FAILURE CAUSES, MECHANISMS AND MODES OF CAPACITORS

\begin{tabular}{|c|c|c|c|c|}
\hline Root Cause & Capacitor Type & Major Failure Mechanism & Major Failure Modes & References \\
\hline \multirow{2}{*}{$\begin{array}{l}\text { High Ambient } \\
\text { Temperature }\end{array}$} & Electrolytic & $\begin{array}{l}\text { Electrolyte evaporation; increase in pressure } \\
\text { inside the capacitor }\end{array}$ & $\begin{array}{l}\text { Capacitance loss, ESR increase; vent opening, in } \\
\text { case of excess internal pressure }\end{array}$ & $\begin{array}{c}21,22,23,25, \\
26 \text { and } 52\end{array}$ \\
\hline & Metallized Film & $\begin{array}{c}\text { Deterioration of quality of electrode } \\
\text { metallization }\end{array}$ & $\begin{array}{l}\text { Change in the non-linearity of current-voltage } \\
\text { characteristics }\end{array}$ & 7,10 and 11 \\
\hline \multirow{2}{*}{$\begin{array}{l}\text { Over Voltage } \\
\text { Stress }\end{array}$} & Electrolytic & $\begin{array}{l}\text { Degradation of oxide film, anode foil } \\
\text { capacitance drop }\end{array}$ & $\begin{array}{c}\text { Increased leakage current flow, capacitance loss, } \\
\text { ESR increase }\end{array}$ & 21,26 and 27 \\
\hline & Metallized Film & Self-healing ("soft failure") & Capacitance loss, ESR increase & $\begin{array}{l}1,5,6,7,8 \\
\quad \text { and } 9\end{array}$ \\
\hline \multirow{2}{*}{$\begin{array}{l}\text { Excess Ripple } \\
\text { Current }\end{array}$} & Electrolytic & Electrolyte evaporation & Capacitance loss, ESR increase & $\begin{array}{c}21232526 \\
\text { and } 52\end{array}$ \\
\hline & Metallized Film & $\begin{array}{l}\text { Electrochemical corrosion; increased core } \\
\text { temperature }\end{array}$ & Capacitance loss, ESR increase & $\begin{array}{l}2,12,13,16 \\
\text { and } 43\end{array}$ \\
\hline \multirow{2}{*}{$\begin{array}{c}\text { Continuous } \\
\text { Charge/ Discharge } \\
\text { Cycle (Pulsed } \\
\text { Discharge) }\end{array}$} & Electrolytic & $\begin{array}{l}\text { Cathode foil capacitance decrease due to } \\
\text { formation of additional dielectric layer; } \\
\text { electrolyte evaporation }\end{array}$ & $\begin{array}{l}\text { Capacitance loss; vent opening, in case of excess } \\
\text { internal pressure due to gas generated during oxide } \\
\text { layer formation }\end{array}$ & 21 and 27 \\
\hline & Metallized Film & Self-healing; electrochemical corrosion & $\begin{array}{l}\text { Capacitance loss, ESR increase; detachment of the } \\
\text { sprayed ends (schoopage) under high electric stress }\end{array}$ & $\begin{array}{c}15,16,44 \text { and } \\
45\end{array}$ \\
\hline Humidity & Metallized Film & $\begin{array}{l}\text { Electrochemical corrosion; dielectric loss due to } \\
\text { moisture absorption by film }\end{array}$ & Capacitance loss, ESR increase & 1,17 and 37 \\
\hline
\end{tabular}

In summary, the life of aluminum electrolytic capacitors depends on environmental and electrical factors. Environmental factors include temperature, humidity, atmospheric pressure, and vibration. Electrical factors include operating voltage, ripple current, and charge-discharge duty cycle. Among these factors, temperature (ambient temperature and internal heating resulting from ripple current) is the most critical to the life of aluminum electrolytic capacitors, whereas conditions such as vibration, shock, and humidity will have little effect on the actual life of the capacitor. Voltage within the allowed operating range has little effect on the actual life expectancy of a capacitor. When the applied voltage is above the rated voltage of the capacitor, the leakage current flow increases at a much faster rate, thus increasing the amount of heat generated [27]. Because a capacitor is essentially an electrochemical device, increased temperatures accelerate the chemical reaction rates within the capacitor (usually a $10^{\circ} \mathrm{C}$ rise in temperature will double the chemical reaction rate) [28].

\section{DEGRADATION MODELING} 3.1. Metallized Film Capacitors Physics-of-Failure-Based Models. Acceleration models predict time-to-failure as a function of stress. Knowledge of the time to reach failure at an accelerated stress level, in conjunction with a calibrated acceleration factor, can be used to predict the equivalent timeto-failure at a different operating stress level. These models are usually based on the physics underlying a failure mechanism. Some common acceleration models used in capacitor lifetime prediction are the Arrhenius and Eyring models for temperature-dependent stresses, and the inverse power law for voltage and humidity stresses.

Arrhenius proposed a chemical kinetics model that showed the temperature dependence of reaction rates. Dakin proposed a lifetime model for electrical insulations, based on the Arrhenius model [29]. Capacitor aging as a function of the temperature follows an Arrhenius law, which is basically an exponential law [1, 30, 31]. The activation energy of a thermal process, as given in the Arrhenius law, is a stressdependent quantity [30]. The experimental observation is that 
simultaneously applied stresses normally produce a degradation effect which is slightly lower than that derived by a simple multiplicative law. Therefore, an interaction term must be added. Eyring theory generalizes Arrhenius law to many factors besides the temperature, and captures the interaction of other stress factors with the temperature stress given in Eq. (1):

$\mathrm{T}_{\text {Eyring }}\left(T_{i}, S_{1}, S_{2}\right)=A_{E} T_{i}^{\alpha} \exp \left(\frac{E_{a}}{k T_{i}}+\left(B_{E}+\frac{C_{E}}{T_{i}}\right) S_{1 i}+\left(D_{E}+\frac{E_{E}}{T_{i}}\right) S_{2 i}\right)$

where TEyring is the useful life of the component, $S_{1 i}$ and $S_{2 i}$ are the supplementary considered stresses, $A_{E}, B_{E}, C_{E}, D_{E}, E_{E}$ and $\alpha$ are the different constants [32]. Simoni [33] and Ramu [34] proposed combined models for thermal and electrical stress, derived from Eyring theory, which take into account the effect of application of electrical stress on the thermal degradation process. The combined-stress life model considering inverse-power electrical life law is given in Eq. (2) as:

$$
L=L_{o}\left[\frac{E}{E_{o}}\right]^{-(n-b T)} \exp (-B T)
$$

In Eq. (2), $n, b$ and $B$ are the model parameters, $L_{o}$ is the life at temperature $\theta_{o}, E_{o}$ is the value of electrical stress below which electrical aging can be neglected, $T\left(=\frac{1}{\theta_{o}}-\frac{1}{\theta}\right)$ is the so-called conventional thermal stress and $\Theta$ is the absolute temperature [35].

Albertini et al. [36] investigate a thermal life model for capacitors subjected to both constant and time-varying temperatures. The constanttemperature life models are based on the Arrhenius model and an Arrhenius-Miner Model is proposed for lifetime calculation under timevarying temperature stress. However, the life estimation by the proposed model is far from accurate when compared to the experimental results, and the temperatures to which capacitors are subjected in the experiment are much higher than the maximum recommended operating temperature (category temperature) of the capacitors.

Regarding voltage and humidity dependency, an inverse power law or an exponential law is generally used [1] [35-38]. An example of a degradation life model simply obtained by multiplying the aging rates of each stress is given in Eq. (3) as:

$$
L=L_{o} \times\left(\frac{R H}{R H_{o}}\right)^{-n_{3}} \times\left(\frac{V}{V_{o}}\right)^{-n_{1}} \times 2^{\frac{T_{o}-T}{n_{2}}}
$$

where $L$ and $L_{0}$ are the lifetime under the use condition and reference condition, respectively. $V$ and $V_{0}$ are the voltages at use condition and reference condition, respectively. $T$ and $T_{0}$ are the temperatures at use condition and reference condition, respectively. $R H$ and $R H_{0}$ are the relative humidity under the use condition and reference condition, respectively. The exponents for voltage, temperature and humidity stresses are denoted by $\mathrm{n}_{1}, \mathrm{n}_{2}$ and $\mathrm{n}_{3}$, respectively.

Data-Driven Models. Acceleration models are most often considered to predict the operating lifetime of capacitors under specific environmental conditions (temperature, voltage and humidity). But the major limitation with these models is the inability to track the capacitor degradation with time. That is, the acceleration models cannot predict the state of health of the capacitor at a particular time. Hence, there is a need for data-driven or statistical degradation models to estimate the capacitor's actual state-of health at a given time and to estimate the remaining useful life (RUL). In non-destructive degradation analysis, once the degradation information has been recorded, the measurements are extrapolated to the pre-defined failure level to estimate the failure time. The common degradation models used to perform extrapolation of data are linear, exponential, power, and logarithmic. In destructive degradation analysis, theoretical population models known as lifetime distribution models are used to describe unit lifetimes, which are probability density functions defined over a range of time. The corresponding cumulative distribution function gives the probability that a randomly selected unit will fail by a specified time. The Weibull model is the most commonly used life distribution model, especially for capacitors. For a selected distribution, a degradation model is typically used to represent the change of the location or log-location parameter with time.

Sometimes there are probabilistic arguments based on the physics of the failure mode that tend to justify the choice of model. Other times, the model is used solely because of its empirical success in fitting actual failure data [39]. In most cases, the end-of-life criterion for metallized capacitors is defined as a $5 \%$ capacitance loss of the initial capacitance [40]. As discussed before, the capacitor degradation rate increases after the capacitance or ESR reaches the specified end-of-life criteria. Hence, the estimation of the capacitor degradation indicators (e.g., capacitance, ESR, $\tan \delta$ ) is of vital importance. Soliman and Wang [41] review the existing condition-monitoring technologies and present the algorithms involved.

Makdessi et al. [42] investigate accelerated aging tests at different temperatures and voltage stresses for metallized film capacitors. The self-healing process is assumed to be a non-homogeneous phenomenon that follows an exponential probabilistic law. A capacitance degradation model is proposed where the model parameters are related to the capacitor at specific voltage and temperature conditions. The model parameters are a function of voltage and temperature and determined by fitting the curve to the experimental points at the applied aging test conditions. The results for the capacitor estimated lifetime are compared with the estimated lifetime given by the Eyring law (1). There is good agreement between the expected lifetimes from both the methods. In [12], a capacitance degradation model under ripple currents is proposed where the model parameter is a constant associated with the characteristic of each type of capacitor related to the gas rate diffusion through the oxide layer.

Hua Li et al. [43] discuss the degradation of metallized film capacitors stressed under a high-temperature, high-humidity environment with an AC voltage. Capacitance and ESR are monitored throughout the experiments and the electro-chemical corrosion phenomenon in two types of metallized films are compared. It is found that the moisture from the surrounding environment takes time to penetrate the capacitor. Before this occurs, the capacitance loss is linear and mainly due to the pre-existing moisture in air trapped between the layers inside the capacitors. The capacitance then decreases faster due to the moisture penetrating effect. The transition time from the first stage to the latter is called as the ingress time of moisture. The capacitance change with time 
before and after the ingress of moisture is given by linear and power degradation models, respectively.

In [37], a set of metallized film capacitors undergo accelerated testing under constant temperature but varying humidity levels. The time-tofailure of the failed capacitors is fitted into a Weibull distribution curve and B1 life, B10 life, and mean time to failure (MTTF) is estimated under the required confidence intervals and the model parameter $n_{3}$ (humidity derating exponent factor) for the lifetime equation (3) is estimated. Li et al. [44] introduce new life prediction models to capture the degradation of metallized film capacitors in pulsed power systems. The capacitance loss is the accumulative result of self-healing in pulsed electrical shots and is divided into two parts: natural loss and sudden loss. The traditional life prediction models are the Weibull distribution model and the regression model, whose parameters are determined by the least squares method. The least-squares method is only appropriate when the capacitance loss is uniform and steady, and the lifetime obtained by the regression model strongly depends on the curve-fitting function (for instance. linear, quadratic, cubic). The BirnbaumSaunders distribution (also known as the fatigue life distribution) is introduced, where the capacitance loss resulting from a fixed number of shots is assumed to be an independent distribution having non-negative random variables. It should obey the normal distribution, whose parameters are first calculated based on experimental data by the method-of-moment estimation algorithm, then used to calculate the lifetime expectancy and variance. However, this life-prediction model does not consider the sudden loss that occurs during lifetime testing of metallized film capacitors. Hence, the Poisson distribution is introduced to analyze the sudden capacitance loss, in which the number of random faults resulting in sudden drop in one shot obeys the law of Poisson distribution. Both the steady capacitance loss and sudden capacitance loss caused by random faults are assumed to be independent, identically distributed, and nonnegative random variables and should obey the law of normal distribution, whose parameters are dependent on the number of shots. Research conducted by Shin et al. [45] uses a similar approach in which the steady or the natural loss is captured by a random variable deterioration method and the sudden loss is captured by a gamma process deterioration method. The deterioration rate of the random variable deterioration model is obtained by using the curve-fitting algorithm, and the shape function and scale parameter of the gamma process is obtained using an expectation-maximization algorithm.

\subsection{Electrolytic Capacitors}

Physics-of-Failure-Based Models. The Arrhenius model is used for the temperature lifetime dependency of electrolytic capacitors. Gualous and Gallay [46] assumed that the capacitor life is proportional to the inverse reaction rate of the process and proposed a modified Arrhenius equation (Eq. (4)).

$$
L=B * e^{\left(\frac{E_{A}}{k T_{o p}}\right)}
$$

In Eq. (4), $\mathrm{L}$ is the expected capacitor life (in hours) for an operating temperature $\mathrm{T}_{\mathrm{op}}$ (in Kelvin), $\mathrm{k}$ is the Boltzmann constant, $\mathrm{E}_{\mathrm{A}}$ is the activation energy, and $\mathrm{B}$ is a material specific parameter.
In industry, the rule of thumb related to the life of electrolytic capacitor is given in Eq. (5):

$$
L=L_{o} * 2^{\left(\frac{T_{o}-T_{o p}}{10}\right)}
$$

where $L$ is the expected life of the capacitor at the operating temperature $T_{o p}$, and $L_{o}$ is the expected life at the rated temperature, $T_{o}$. This means that for every $10^{\circ} \mathrm{C}$ increase in operating temperature, the life of the electrolytic capacitor reduces by half $[23,28,47]$. The temperature acceleration factor is approximately two over an ambient temperature range from $60^{\circ} \mathrm{C}$ to $95^{\circ} \mathrm{C}$. However, according to the Arrhenius equation, the reciprocal of $T$ is directly proportional to the logarithm of lifetime, which means that, strictly speaking, there is the temperature range where the theory of lifetime reducing by half for every $10^{\circ} \mathrm{C}$ rise is not applicable. Especially for capacitors whose maximum operating temperature is $105^{\circ} \mathrm{C}$ or higher, the temperature acceleration factor needs to be modified depending on temperature ranges of the lifetime estimation [28].

Dehbi and Wondrak [48] slightly modified the model given by Eq. (5) to account for the applied voltage. Jánó and Pitica [49] combined the Dehbi and Wondrak's [48] and Gualous and Gallay's [46] models and proposed the following (Eq. (6)):

$$
L=B * e^{\left(\frac{E_{A}}{k T_{o p}}\right)} *\left(\frac{V_{o}}{V}\right)^{n}
$$

in which $V_{o}$ is the maximum rated voltage, $V$ is the operating voltage and $n$ is the capacitor type parameter ( 0 for axial, 1 for radial). This suggests that only radial capacitors are affected by working voltages.

The most common monitoring methods for degradation of capacitor with operational time include ESR-based monitoring. Changes in chemical and physical properties of the capacitor electrolyte will affect the value of ESR $[50,51]$. The conductivity of the capacitor electrolyte increases because of a rise in the temperature, hence the value of the ESR will decrease with increasing temperature, accompanied by a rise in the capacitance value. Gasperi [52] proposed an algorithm to estimate the ESR of an electrolytic capacitor. A commonly used rule-of-thumb is that a capacitor reaches the end of life when it has lost about $40 \%$ of its electrolyte, that is, when the ESR increases to roughly 2.7 times of the initial value. Gasperi related the volume of electrolyte to the ESR of the capacitor as Eq. (7):

$$
\frac{E S R}{E S R_{o}}=\left(\frac{V_{o l-i}}{V_{o l}}\right)^{2}
$$

where, $E S R_{o}$ is the initial ESR, $V_{o l}$ is the volume of electrolyte, and $V_{o l}$ $i$ is the initial volume of electrolyte.

The rate of electrolyte loss is assumed to be directly proportional to the vapor pressure of the electrolyte. Since vapor pressure is temperature dependent, the core temperature of the capacitor critically affects the vapor pressure inside the capacitor and knowing the core temperature (ambient temperature + heat rise by ripple current), the vapor pressure of the capacitor can be estimated by an exponential relation between the vapor pressure of the electrolyte and the core temperature [52]. 
Kulkarni et al. [22] presented the capacitance and ESR degradation models as a function of electrolyte volume loss, by analyzing the geometry of the capacitor (Eq. (8.1) and Eq. (8.2)).

$$
\begin{gathered}
C(t)=\left[\frac{2 \varepsilon_{R} \varepsilon_{o}}{d_{C}}\right]\left[\frac{V_{o l-i}-V_{d o l}(t)}{j_{e o} t w_{e}}\right] \\
E S R(t)=\left[\frac{\rho_{E} d_{C} P_{E}}{2}\right]\left[\frac{j_{e o} t w_{e}}{V_{o l-i}-V_{d o l}(t)}\right]
\end{gathered}
$$

In these models, $t$ is the aging time, $V_{d o l}$ is the dispersion volume at time $t, \rho_{E}$ is electrolyte resistivity, $d_{C}$ is cathode oxide layer thickness, $\varepsilon_{R}$ is relative dielectric constant, $\varepsilon_{o}$ is permittivity of free space, $w_{e}$ is the volume of ethylene glycol molecules, $j_{e o}$ is evaporation rate, and $P_{E}$ is the correlation factor related to electrolyte spacer porosity and average electrolyte pathway. It is clearly seen by the models that, as the electrolyte volume decreases, the capacitance decreases and the ESR increases.

Data-Driven Models. In the research work by Kulkarni et al. [53], the capacitor degradation parameters are observed under nominal conditions. ESR drift as a function of time is determined by the Arrhenius model, given in Eq. (9):

$$
\frac{1}{E S R_{t}}=\frac{1}{E S R_{o}}\left(1-k \cdot t \cdot \exp \left(\frac{-E}{T+273}\right)\right)
$$

where $t$ is the operating time, $E S R_{t}$ is the ESR value at $t, T$ is the temperature in degree Celsius at which the capacitor operates, $E S R_{0}$ is the initial ESR value when $t$ is equal to $0, k$ is a constant which depends on the design and the construction of the capacitor and $E$ is the activation energy defined by Boltzmann's constant. A third-degree regression model, determined to be the best fit by least squares, is proposed for the average capacitance degradation with time. In [54], capacitance loss with time under overvoltage conditions is captured by an exponential degradation model and the model parameters are estimated by a nonlinear least-squares regression algorithm.

The values of capacitance and the ESR vary both with time and the ambient temperature. Abdennadher et al. [55] proposed an aging algorithm for real-time condition monitoring of capacitors to determine the RUL of electrolytic capacitors used in uninterruptible power supplies. For a given ambient temperature of the capacitor, the total lifetime is given by the Arrhenius equation. Also, at that particular temperature, the ideal value of ESR or capacitance are obtained by curve-fitting equations. The actual or degraded value of capacitance or ESR is obtained from the experiment at a given time, which gives the operating time of capacitor at those values by curve-fitting equations. Subtracting the operating time - obtained by curve- fitting equations from the total lifetime obtained by Arrhenius equation yields the RUL. Similar degradation modeling is completed in [56], where the relationship between temperature and the instantaneous value of ESR and capacitance is modeled by an inverse exponential and linear degradation model, respectively, and the model parameters are calculated with a least-square fitting method. When the ambient temperature and the degradation rate are constant, the evolution of ESR and capacitance with time are given by exponential and linear degradation models, respectively. Based on these statistical equations, a life prediction model for electrolytic capacitors operating at a constant temperature has been proposed to find the RUL as defined by the minimum residual life of either capacitance or ESR end-of-life criteria, whichever is shorter.

Under thermal and voltage stresses, the temperature of the capacitor hotspot continuously increases. More recently, Sun et al. [57] proposed a hybrid degradation model by combining the physics-of-failure model with a similar statistical model of capacitance and ESR degradation with time at constant capacitor temperature, where model parameters are assumed to follow the Arrhenius equation, as given in Eqs. (10.1) (10.4).

$$
\begin{gathered}
C(t)=C_{o} \cdot(1+A \cdot t) \\
E S R(t)=E S R_{o} \cdot e^{B \cdot t} \\
A(t)=A_{o} \cdot e^{\frac{-E_{a 1}}{(k \cdot T)}} \\
B(t)=B_{o} \cdot e^{\frac{-E_{a 2}}{(k \cdot T)}}
\end{gathered}
$$

Here, $C_{o}$ and $E S R_{o}$ are the initial capacitance and ESR, respectively, $A$ and $B$ describe temperature-dependent degradation rates, $A_{0}$ and $B_{0}$ are base degradation rates, $E_{a l}$ and $E_{a 2}$ are the activation energies, and $\kappa$ is the Boltzmann constant. These models are then combined and integrated to obtain variable-temperature capacitance and ESR degradation models.

In [58], accelerated life tests on aluminum electrolytic capacitors under temperature and voltage stress are conducted to study the effect of applied voltage and ambient temperature on the capacitor. The degradation of the capacitor is studied by measuring its capacitance loss at random times over the test duration and a regression equation representing the degradation pattern is developed, which is used to predict the time to failure of each capacitor. Weibull analysis for the predicted failure times of all the capacitors at each stress level (voltage, temperature) is carried out and the MTTF of the population at that stress level is calculated. Analysis of variance (ANOVA) is also carried out in MINITAB software to determine which of the two stress factors has more effect on the life of capacitor and how the interaction effect between these two stresses impacts the life of the capacitor. It is found that the applied voltage affects the mean life most, followed by ambient temperature and interaction effect. A regression equation that correlates the life of a capacitor with both stress levels is obtained that can be used to predict the life when the capacitor is used beyond the experimental stress levels. Table 2 summarizes the most significant research work associated with the various stress types in capacitors. 
TABLE 2. RESEARCH WORK ASSOCIATED WITH THE VARIOUS STRESS TYPES IN CAPACITORS

\begin{tabular}{|c|c|c|c|}
\hline Stress Type & Reference & Model Used & Major Contribution \\
\hline \multicolumn{4}{|c|}{ Metallized Film Capacitors } \\
\hline Temperature & {$[36]$} & Arrhenius model & $\begin{array}{l}\text { Life model proposed for time-varying thermal stress, using Miner's cumulative } \\
\text { damage theory }\end{array}$ \\
\hline DC Voltage, Temperature & {$[42]$} & $\begin{array}{l}\text { Exponential regression equation, } \\
\text { Eyring law }\end{array}$ & $\begin{array}{l}\text { Capacitance degradation with time; constant high temperature and voltage. } \\
\text { Lifetime estimated by regression model and Eyring law }\end{array}$ \\
\hline Ripple Current & [12] & $\begin{array}{l}\text { Regression equation, based on } \\
\text { underlying physics-of-failure }\end{array}$ & $\begin{array}{l}\text { Electrochemical corrosion introduced as a failure mechanism in presence of } \\
\text { ripple current. Regression equation proposed for capacitance loss with time } \\
\text { based on theory of the oxidation kinetics. }\end{array}$ \\
\hline \multirow[t]{2}{*}{ Pulsed Discharge } & [44] & $\begin{array}{c}\text { Birnbaum-Saunders distribution } \\
\text { (fatigue life distribution), Poisson } \\
\text { distribution }\end{array}$ & $\begin{array}{l}\text { Standard life prediction models (regression, Weibull) are compared with the } \\
\text { newly introduced Birnbaum-Saunders distribution (to model steady } \\
\text { capacitance loss) and Poisson distribution (to model sudden capacitance loss) } \\
\text { for pulsed power applications. }\end{array}$ \\
\hline & [45] & $\begin{array}{l}\text { Random variable deterioration } \\
\text { method, Gamma process } \\
\text { deterioration model }\end{array}$ & $\begin{array}{l}\text { Steady capacitance loss is modeled by random variable deterioration method } \\
\text { and sudden loss is modeled by a gamma process deterioration method. }\end{array}$ \\
\hline $\begin{array}{l}\text { AC Voltage, Temperature, } \\
\text { Humidity }\end{array}$ & [43] & Regression equation & Capacitance and ESR modeling according to the "ingress time" of moisture \\
\hline Humidity, Temperature & [37] & $\begin{array}{c}\text { Weibull distribution, } \\
\text { combined model (Arrhenius } \\
\text { model + inverse power law for } \\
\text { humidity) }\end{array}$ & $\begin{array}{l}\text { Time to failure is fitted into a Weibull distribution curve and B1 life, B10 life } \\
\text { and MTTF are estimated under the required confidence intervals and the model } \\
\text { parameter for the lifetime equation is estimated for all lifetime definitions. }\end{array}$ \\
\hline \multicolumn{4}{|c|}{ Electrolytic Capacitors } \\
\hline \multirow{3}{*}{ Temperature } & [52] & Arrhenius equation & $\begin{array}{l}\text { Physics-of-failure model to predict ESR change with electrolyte loss is } \\
\text { proposed. Lifetime of capacitors at different temperatures is calculated using } \\
\text { Arrhenius law, and the results are compared to lifetimes obtained via an } \\
\text { approximation law used in industry. }\end{array}$ \\
\hline & [55] & $\begin{array}{l}\text { Regression equation, } \\
\text { Arrhenius equation }\end{array}$ & $\begin{array}{l}\text { For a given ambient temperature of the capacitor, the total lifetime is given by } \\
\text { the Arrhenius equation. The operating time of the capacitor is obtained using } \\
\text { regression equations characterizing capacitance and ESR with time and } \\
\text { temperature, respectively. Remaining useful life is estimated by subtracting } \\
\text { total lifetime with the operating time obtained by regression equations. }\end{array}$ \\
\hline & [57] & $\begin{array}{l}\text { Regression equation, } \\
\text { Arrhenius equation }\end{array}$ & $\begin{array}{l}\text { Hybrid degradation modeling approach is proposed in which the parameters of } \\
\text { regression equations characterizing capacitance and ESR with time, follow } \\
\text { Arrhenius law. Increase in output current is considered as a failure criterion. } \\
\text { Time to failure can be calculated at variable-temperature operating conditions. }\end{array}$ \\
\hline Temperature, Voltage & [49] & $\begin{array}{l}\text { Combined model (Arrhenius }+ \\
\text { inverse power) }\end{array}$ & $\begin{array}{l}\text { A new prediction method for capacitor lifetime is introduced. The lifetime } \\
\text { obtained is found to be more accurate than the previous models. This prediction } \\
\text { methodology suggests that only radial capacitors are actually affected by } \\
\text { working voltages. }\end{array}$ \\
\hline Voltage & {$[54]$} & Regression equation & $\begin{array}{l}\text { A remaining useful life prediction methodology for electrolytic capacitors } \\
\text { based on Kalman filter is presented. }\end{array}$ \\
\hline Nominal Conditions & [53] & $\begin{array}{l}\text { Regression equation, } \\
\text { Arrhenius equation }\end{array}$ & $\begin{array}{l}\text { Under nominal conditions (below rated voltage and temperature), ESR drift as } \\
\text { a function of time is determined by Arrhenius model (exponential model). A } \\
\text { third-degree regression model is proposed for the average capacitance } \\
\text { degradation with time. }\end{array}$ \\
\hline
\end{tabular}

\section{DISCUSSION}

Although electrolytic capacitors are a popular choice for the DC-link applications due to high capacitance values, they generally have a low reliability and a short shelf life, mainly due to their sensitivity to temperature variations. Metallized polymer film capacitors, especially the capacitors with polypropylene as a dielectric, can be considered as a good substitute for electrolytic capacitors in fault-tolerant applications because of their low temperature and frequency dependency, and very little change of capacitance with time under voltage applications due to their unique self-healing ability. The insulation resistance as a failure indicator has been largely neglected in the existing research, but it severely affects the capacitor degradation, contributing to phenomenon like thermal runaway, especially in high-DC-voltage conditions. Hence, both capacitance loss and decrease in insulation resistance should be considered to access the complete health of metallized film capacitor. There is a need for real-time capacitor degradation models that take into account the operating conditions (ambient temperature, voltage, ripple current, humidity, frequency, time, etc.) for more accurate stress analysis. Also, an investigation into the interaction effect among various stressors on the lifetime of capacitors needs to be conducted [30]. There is a need for hybrid models, which combine the physics-of-failure and data-driven models, for capturing the capacitor degradation more realistically. This is particularly needed in the case of metallized film capacitors, as little research has been published in this area apart from the work of Makdessi et al. [12, 42]. Also, regression-based degradation modeling seems to be the most widely used among the data-driven approaches. But regression-based models require large sample sets to 
increase their predictive accuracy. In regression analysis, many variables are susceptible to noise in the data or certain unnecessary information, therefore reducing the prediction power of regression analysis. Grey models may provide better performance using small sample size, not only in model fitting, but also in forecasting [59].

\section{ACKNOWLEDGMENTS}

This work was authored in part by Alliance for Sustainable Energy, LLC, the manager and operator of the National Renewable Energy Laboratory for the U.S. Department of Energy (DOE) under Contract No. DE-AC36-08GO28308. The views expressed in the article do not necessarily represent the views of the DOE or the U.S. Government. The U.S. Government retains and the publisher, by accepting the article for publication, acknowledges that the U.S. Government retains a nonexclusive, paid-up, irrevocable, worldwide license to publish or reproduce the published form of this work, or allow others to do so, for U.S. Government purposes.

\section{REFERENCES}

[1] Gallay, R. "Metallized Film Capacitor Lifetime Evaluation and Failure Mode Analysis." Proceedings of the CAS-CERN Accelerator School: Power Converters: pp. 45-56. May 2014.

[2] Reed, C.W. and Cichanowskil, S.W. "The Fundamentals of Aging in HV Polymer-film Capacitors." IEEE Transactions on Dielectrics and Electrical Insulation Vol. 1 No. 5 (1994): pp. 904-922.

[3] Vishay application notes. "Characteristics and Definitions used for Film Capacitors." Document No. 28147. 2008.

[4] Mach, P. and Horak, M. "Examination of Influence of Electrical Stress on Parameters of PP Film Capacitors." IEEE 20th International Symposium for Design and Technology in Electronic Packaging: pp. 51-54. Oct. 2014.

[5] Gebbia, M. "Introduction to Film Capacitors." Illinois Capacitor, Inc. 2013.

[6] Qin, S., Ma, S., and Boggs, S. A. "The Mechanism of Clearing in Metalized Film Capacitors." IEEE International Symposium on Electrical Insulation: pp. 592-595. June 2012.

[7] Flicker, J., Kaplar, R., Marinella, M., and Granata, J. "Lifetime Testing of Metallized Thin Film Capacitors for Inverter Applications." IEEE 39th Photovoltaic Specialists Conference: pp. 3340-3342. June 2013.

[8] Schneuwly, A., Gröning, P., and Schlapbach, L. "Uncoupling Behaviour of Current Gates in Self-Healing Capacitors." Materials Science \& Engineering B Vol. 55 No. 3 (1998): pp. 210-220.

[9] Emel'yanov, O., "Electrodynamic Thermal Breakdown of a Capacitor Insulator.” Technical Physics Vol. 56 No. 11 (2011): pp. 1685-1688.

[10] Li, H., Li, H., Li, Z., Lin, F., Wang, W., Wang, B., Huang, X., and Guo, X. "Temperature dependence of self-healing characteristics of metallized polypropylene film." Microelectronics Reliability Vol. 55 No. 12 (2015): pp. 2721-2726.
[11] Mach, P., Horak, M., and Stancu, C. "Thermal Ageing of Polypropylene Film Capacitors." 38th International Spring Seminar on Electronics Technology: pp. 272-276. May 2015.

[12] Makdessi, M., Sari, A., Venet, P., Bevilacqua, P., and Joubert, C. "Accelerated Ageing of Metallized Film Capacitors under High Ripple Currents Combined with a DC Voltage." IEEE Transactions on Power Electronics Vol. 30 No. 5 (2015): pp. 2435-2444.

[13] El-Husseini, M. H., Venet, P., Al-Majid, A., Fathallah, M., Rojat, G., and Ferreira J.A. "Manufacturing technology effect on current pulse handling performance of metallized polypropylene film capacitors." Journal of Physics D: Applied Physics Vol. 36 No. 18 (2003): pp. 22952303.

[14] Cavallini, A., Fabiani, D., Mazzanti, G., and Montanari, G.C. "Models for Degradation of Self-healing Capacitors Operating under Voltage Distortion and Temperature." Proceedings of the 6th International Conference on Properties and Applications of Dielectric Materials: pp. 108-111. June 2000

[15] Lin, F., Dai, X., Li, J., Yao, Z., and Wang, N. "On the failure mechanism of metallized polypropylene pulse capacitors." Conference on Electrical Insulation and Dielectric Phenomena, Annual Report Vol. 2 (2000): pp. 592-595.

[16] Borghetti, A., Nucci, C.A., Pasini, G., Pirani, S., and Rinaldi, M. "Tests on self-healing metallized polypropylene capacitors for power applications." IEEE Transactions on Power Delivery Vol. 10 No. 1 (1995): pp. 556-561.

[17] Brown R. W. "Linking Corrosion and Catastrophic Failure in LowPower Metallized Polypropylene Capacitors." IEEE Transactions on Device and Materials Reliability Vol. 6 No. 2 (2006): pp. 326-333.

[18] El-Husseini, M.H., Venet, P., Rojat, G., and Fathallah, M. "Effect of the Geometry on the Aging of Metalized Polypropylene Film Capacitors." IEEE 32nd Annual Power Electronics Specialists Conference: Vol. 4 pp. 2061-2066. June 2001.

[19] MIL-C-62F. "General specification for capacitors." Military Specifications and Standards. 2008.

[20] IEC-60068-1. "Environmental testing, part 1: General and guidance." IEC Standards. 1988.

[21] Kulkarni, C. "A physics-based degradation modeling framework for diagnostic and prognostic studies in electrolytic capacitors.” Ph.D. Dissertation. Vanderbilt University. 2013.

[22] Kulkarni C., Jose C., Biswas G., and Goebel K. "Physics Based Electrolytic Capacitor Degradation Models for Prognostic Studies under Thermal Overstress." 1st European Conference of the Prognostics and Health Management Society. 2012.

[23] Albertsen, A. "Electrolytic Capacitor Lifetime Estimation." Jianghai. 2010.

[24] Perisse, F. "Etude et analyse des modes de d'efaillances des condensateurs electrolytiques a l'aluminium et des thyristors, 
appliqu'ees au syst'eme de protection du LHC (Large Hadron Collider)." Master's thesis. Claude Bernard University. 2003.

[25] Lahyani A., Venet P., Grellet G., and Viverge P.J. "Failure prediction of electrolytic capacitors during operation of a switchmode power supply." IEEE Transactions on Power Electronics. Vol. 13 No. 6 (1998). pp. 1199 - 1207.

[26] Shrivastava A., Bangerth S., Azarian M., Morillo C., Pecht M., Levin M., Steinhardt L., and Callini A. "Detection of capacitor electrolyte residues with FTIR in failure analysis." Journal of Materials Science: Materials in Electronics Vol. 25 No. 2 (2014): pp. 635 - 645.

[27] Imam A. M., Divan D. M., Harley R. G., and Habetler T. G. "Electrolytic Capacitor Failure Mechanism Due to Inrush Current." IEEE Industry Applications Annual Meeting: pp.730-736. Sept. 2007.

[28] Technical Notes. "Judicious Use of Aluminum Electrolytic Capacitors." Nippon Chemi-Con.

[29] Dakin T. W. "Electrical Insulation Deterioration Treated as a Chemical Rate Phenomenon." Transactions of the American Institute of Electrical Engineers Vol.67 No. 1 (1948): pp.113-122.

[30] Wang H. and Blaabjerg F. "Reliability of Capacitors for DC-Link Applications in Power Electronic Converters-An Overview." IEEE Transactions on Industry Applications Vol. 50 No. 5 (2014): pp. 3569 -3578 .

[31] Escobar L. A. and Meeker W. Q. "A Review of Accelerated Test Models.” Statistical Science, Vol. 21, No. 4 (2006): pp. 552-577.

[32] S. Glasstone, K. J. Laidler, and H. E. Eyring. "The Theory of Rate Processes.” McGraw Hill, New York. 1941.

[33] L. Simoni, "General Equation of the Decline in the Electric Strength for Combined Thermal and Electrical Stresses." IEEE Transactions on Electrical Insulation Vol. 19 No. 1 (1984): pp. 45-52.

[34] B. Hemalatha and T. S. Ramu. "Insulation Degradation under Multifactor Stress." Fifth International Symposium on High Voltage Engineering. August 1987.

[35] Montanari G. C. and Simoni L. "Aging Phenomenology and Modeling." IEEE Transactions on Electrical Insulation Vol. 28 No. 5 (1993): pp. 755-776.

[36] Albertini, A., Masi, M. G., Mazzanti, G., Peretto, L., and Tinarelli, R. "Toward a BITE for Real-Time Life Estimation of Capacitors Subjected to Thermal Stress." IEEE Transactions on Instrumentation and Measurement Vol. 60 No. 5 (2011): pp. 1674-168.

[37] Wang, H., Diaz R. P., and Blaabjerg F. "A Humidity-Dependent Lifetime Derating Factor for DC Film Capacitors." IEEE Energy Conversion Congress and Exposition: pp. 3064-3068. Sept. 2015.

[38] Peck D. "Comprehensive model for humidity testing correlation." 24th International Reliability Physics Symposium: pp. 44-50. April 1986.

[39] NIST/SEMATECH “e-Handbook of Statistical Methods.” http://www.itl.nist.gov/div898/handbook/apr/section1/apr16.htm
[40] W. J. Sarjeant, J. Zirnheld, and F. W. MacDougall. "Capacitors." IEEE Transactions on Plasma Science Vol. 26 No. 5 (1998). pp. 13681392.

[41] Soliman H., Wang H., and Blaabjerg F. "A Review of the Condition Monitoring of Capacitors in Power Electronic Converters." IEEE Transactions on Industry Applications Vol. 52 No. 6 (2016): pp. 4976-4989.

[42] M. Makdessi, A. Sari, and P. Venet, "Metallized polymer film capacitors ageing law based on capacitance degradation." Microelectronics Reliability Vol. 54 No. 9-10 (2014): pp. 1823-1827.

[43] Li H., Lewin P., and Fothergill J. C. “Aging Mechanisms of X2 Metallized Film Capacitors in a High Temperature and Humidity Environment." IEEE International Conference on Dielectrics: pp. 804807. July 2016.

[44] Li Z., Li H., Lin F., Chen Y., Liu D., Wang, B., Zhang, Q., and He W. "Lifetime Prediction of Metallized Film Capacitors Based on Capacitance Loss.” IEEE Transactions on Plasma Science Vol. 41 No. 5 (2013): pp. 1313-1318.

[45] Shin, S., Ham, H., and Lee, H. "Lifetime Prediction of DC-Link Film Capacitors using a Stochastic Model Combined by Random Variable and Gamma Process." SAE Int. J. Passeng. Cars - Electron. Electr. Syst. Vol. 7 No. 2 (2014): pp. 544-551.

[46] H. Gualous, R. Gallay, G. Alcicek, B. Tala-Ighil, A. Oukaour, B. Boudart, and P. Makany. "Supercapacitor Ageing at Constant Temperature and Constant Voltage and Thermal Shock." Microelectronics Reliability Vol. 50 No. 9 (2010): pp. 1783 - 1788.

[47] S. G. Parler. "Deriving life multipliers for electrolytic capacitors." IEEE Power Electronics Society Newsletter Vol. 16 No. 1 (2004): pp. $11-12$.

[48] A. Dehbi, W. Wondrak, Y. Ousten, and Y. Danto. "High Temperature Reliability Testing of Aluminum and Tantalum Electrolytic Capacitors." Microelectronics Reliability Vol. 42 No. 6 (2002): pp. 835-840.

[49] R. Jánó and D. Pitica. "Accelerated Ageing Tests of Aluminum Electrolytic Capacitors for Evaluating Lifetime Prediction Models." Acta Technica Napocensis Vol. 53 No. 2 (2012): pp. 36.

[50] L. J. Hart and D. Scoggin. "Predicting Electrolytic Capacitor Lifetime.” Powertechnics Magazine pp. 24-29. Oct. 1987.

[51] J. A. Lauber. "Aluminum Electrolytic Capacitors-Reliability, Expected Life and Shelf Capability." Sprague Technical Paper TP83-9 pp. 4. 1985.

[52] M. L. Gasperi. "Life prediction model for aluminum electrolytic capacitors." in Industry Applications Conference, 31st IAS Annual Meeting Vol. 3: pp. 1347-1351. 1996.

[53] Kulkarni C., Biswas G., Koutsoukos X., Celaya J., and Goebel K. "Experimental Studies of Ageing in Electrolytic Capacitors." Annual Conference of the Prognostics and Health Management Society. 2010. 
[54] Celaya J., Kulkarni C., Biswas G., Saha S., and Goebel K. "A Model-based Prognostics Methodology for Electrolytic Capacitors Based on Electrical Overstress Accelerated Aging." Annual Conference of the Prognostics and Health Management Society. October 2011.

[55] Abdennadher K., Venet P., Rojat G., Retif J. M., and Rosset C. “A Real-Time Predictive-Maintenance System of Aluminum Electrolytic Capacitors Used in Uninterrupted Power Supplies." IEEE Transactions on Industry Applications Vol. 46 No. 4 (2010): pp. 1644-1652.

[56] Yu Y., Zhou T., Zhu M., and Xu D. "Fault Diagnosis and Life Prediction of DC-link Aluminum Electrolytic Capacitors used in threephase AC/DC/AC converters." Second International Conference on Instrumentation \& Measurement, Computer, Communication and Control: pp. 825-830. December 2012.

[57] Sun B., Fan X., Qian C., and Zhang G. "PoF-Simulation-Assisted Reliability Prediction for Electrolytic Capacitor in LED Drivers." IEEE Transactions on Industrial Electronics Vol. 63 No. 11 (2016): pp. 67266735.

[58] Naikan V.N.A. and Rathore A. "Accelerated temperature and voltage life tests on aluminium electrolytic capacitors: A DOE approach." The International Journal of Quality \& Reliability Management Vol. 33 No. 1 (2016): pp. 120-139.

[59] Wang, F., Lu, Y., and Chu, T. "Applying grey model to predict the useful lifetime for high-power white LEDs." Optical and Quantum Electronics Vol. 48 No. 1 (2016): pp. 1-15. 